\title{
The Human Factor: The Most Important Asset for Successful Integration of Information and Communication Technologies in Education
}

\author{
Mohammed Amine BRAHAMI \\ Oran Higher School of Economics, BP 65 CH 2 Achaba Hnifi, \\ Technopôle de l'USTO. 31000 Oran. Algeria
}

\begin{abstract}
Laboratory of Research in Analytical and Operational Methodological Applications in Economics Abstract

The human factor may be the key to success as far as effectively integrating information and communication technologies into education are concerned. It can also represent the most unavoidable obstacle that prevents to reach this mostly aimed at achievement. As a matter of fact, to attain a satisfactory situation of ICT equipment with favorable indicators such as an ideal computer / student ratio, an internet connection available in all schools, teachers with private facilities, certainly does not mean that the result will be a thriving integration of ICT into education. This contribution provides a theoretical and empirical perspective concerning this issue with a case study of Algerian schools, revealing that the human factor represented by school directors, teachers, technical support staff, staff to monitor students using computers, is the most important asset for successful integration of ICT in education.
\end{abstract}

Keywords: human factor, integration, ICT, education

DOI: $10.7176 / \mathrm{JEP} / 11-6-18$

Publication date: February $29^{\text {th }} 2020$

\section{Introduction}

Pedagogical situations: Indeed, the uses of computers for educational ends change the activities of teachers. In this sense, education stakeholders, especially teachers and school leaders, must innovate in order to claim ICTs in their favor. In these pedagogical situations, which sometimes are prepared by the teacher in advance in educational scenarios, the third player in education who is the students, suffer the repercussions of the integration of ICT. If it is well prepared it will increase the chances of success. To this end, several results state that ICT have a very positive impact on student learning, especially since they are a factor encouraging this integration. In addition, for many years now, the place and role of ICT in education have been a source of debate. Indeed, the use of ICTs in education is an important issue to consider, especially in relation to the education partners. Likewise, their integration into education has preoccupied the attention of governments as well as researchers or actors in the educational system, [1], [2],[3]. Moreover, it is very difficult to answer the question of how to successfully integrate ICT into education? Integration is defined as an implantation of a novelty; it is also assimilated to a form of unity, of association itself in the spirit of renewal or repair. In education it provides human or material support. The latter is most often represented by educational materials, including ICTs that are used for educational means. According to, [4], there is not necessarily a pedagogy adjusted to any new technology. Therefore, the education staff mainly the teachers, must make benefit of the tool and use them appropriately. Undoubtedly, the phrase 'use ICTs in education' points to their use. Indeed, it is the most suitable in this case because it specifies an action to act old and recent. It corresponds to an interpretation of the integration of ICT in education and reinforces it by inducing a sense of habit. For many researchers and specialists in education, for there to be use, it is necessary to convince the teachers of the pedagogical interest of the technologies and to make out the ideal is necessary to convince teachers of the pedagogical interest of technology and teaching technologies, [5], [6].

In addition, there are several models and experiences of integrating ICT into education in several countries. However, their application requires a minimum of favorable conditions for the integration of ICT at least, good equipment and initial and continuous training of teachers. However, experiences have shown that if the conditions for ICT integration are met, it does not necessarily mean that there will be ICT integration. The successful integration of ICT has required the involvement of all actors in education.

\section{Theoretical frame}

The relative power of a country's ICT can be measured by the level of ICT use by its citizens. This is the reason why it has led all countries to work to instill in the younger generation a new way of life which is that of communicating, working, exchanging, studying and even playing using ICT. Concretely, taming ICTs by young citizens starts at school and even well before. The integration of ICTs in young people's lives starts very early, but it is implemented over time by following the evolution of technological innovations and the development of new technologies (Educational technology, Artificial Intelligence, Machine Learning ...). The level of ICT integration 
in society can even be shown as a unit of measurement and ranking of a country's development. All countries give it growing importance, it has become a strategic level embodied in the policies of each country. However, evaluating an ICT integration approach remains difficult but above all complex. Experiences of ICT integration in education have shown positive results in some countries. But in other countries this has not been the case, or the objectives have not been achieved. Even though, the latest ICT development data from the ITU (International Telecommunication Union) of 2017 has shown continued progress in connectivity and ICT use. Resulting from the growth of the fixed and mobile broadband infrastructure in many countries of the world is stimulating access to the Internet and its use. Nevertheless, this does not in all cases interpret a positive correlation with the same intensity in education.

In order to have a realistic idea about the integration of ICT in education, we have chosen to mention some studies that have been carried out in the field in order to benefit from the experiences of one and the other, namely; [7], [8], [9], [10], [11], [12], [13], [14].Of the process (Visi-TIC) of Coen and Schumacher who moreover presented a well structured summary table to the systemic model of innovation of Depover and Strebelle. The four authors agreed on number three; the systemic model of Depover and Strebelle presents three levels of integration of innovation in education and the process of integration of ICTs of Coen and Schumacher assesses the degree of integration of ICTs on the subject's responses to the number of three, thus he can situate the level of ICT integration on a three-level scale. Indeed, these models measure the degree of integration of ICT in education, which can be used by different countries seeking to verify the level of integration. But these models assume that there should be integration first, in order to apply them. Other studies demonstrate the path teachers need to take to achieve full ICT integration in their classroom. In particular, there needs to be transition from training to the use of ICT or practice to reach a sense of self-efficacy. Heer and Akkari insist that the effective integration of ICTs cannot be achieved without supporting training, they place great importance on the training of teachers in the use of ICT in the classroom. Isabelle, Lapointe and Chiasson focused on the role of school principals in bringing ICT into the classroom. In analyzing the results of their survey, they conclude that the more managers feel comfortable with ICT, the more they support teachers in their integration. Finally, for Boéchat-Heer, who did a study on the integration of MITIC ${ }^{1}$ into the classroom in schools, the results of his study are in agreement with those of Heer and Akkari. They point out that, despite good equipment, teachers do not use ICT (MITIC) in practice and even the fact that they have received initial training the result has not changed. Indeed, these studies are useful and important for any country that is interested in integrating ICT into education. Because, they have demonstrated that even with good equipment and initial and continuous training of teachers, the use of ICT in education has not been of the expected level. Karsenti and Larose point out that it is not an easy task to become an exemplary user of information and communication technologies. Because, according to the authors: " c'est un processus complexe, non linéaire, qui s'échelonne sur plusieurs années." 2

Therefore, the integration of ICT in education does not mean a radical change in teaching methods. Education actors, mainly teachers and school directors, must accept this promising change in order to be able to integrate it into their old ways of operating. Unanimously, all specialists in teaching and learning agree that the machine will never replace the teacher. Indeed, it is the hard core of learning, including the one applying the constructivist approach, which seems to us the most appropriate for the integration of ICT in education. Likewise, several ICT integration processes exist, and are applied all over the world. But those who have given more or less satisfaction, are built on an approach around the human factor because the realization of the integration of ICT in education cannot be done without the human factor that can be substituted by the directors of institutions; teachers and technical support staff; allowing them to follow the very rapid evolution of ICT.

\section{Methodology}

In Algeria, the ministerial authorities of national education recognize the importance of integrating ICT into teaching and learning, both to prepare students for the new digital society and to make the most of the new technologies and technological tools for pedagogy. Important investments have been undergone in the last twelve years to equip ICT institutions and connect them to the Internet. Indeed, this action was intended to familiarize the young generation, teachers and school directors with the new technologies so that it becomes an asset in favor of education and in everyday life, in particular, the one in the process of digitization. In this sense, based on the purpose which is to collect information on the reality of the integration of ICT in education, two main axes were studied: a survey of school principals on the school environment (equipment of schools) schools, the relevance and impact of ICT, the main factors considered as obstacles to the integration of ICT ...). Another was realized among teachers of these institutions dealing with their personal skills, as well as the integration of ICT in their professional practice. The first step of our research was descriptive in nature. Indeed, the descriptive aspect in one's research, allowed one to give a real vision of the situation of the integration of ICT in education. Two

\footnotetext{
${ }^{1}$ MITIC : Médias, Image, Technologies de l'Information et de la Communication

2 Translated: "it's a complex, non-linear process that goes on over many years".
} 
questionnaires were designed: a first questionnaire for a sample of school directors, and a second questionnaire sent to another group of teachers. For methodological reasons, data collection was based on paper questionnaires only. Thus, both questionnaires contained closed questions (single responses, checkboxes), and the questionnaires offered comment boxes at the end of the questions. The survey focused on one of the largest cities in Algeria, the city of Oran. The survey on the use of ICTs was conducted with a sample of 198 subjects, 17 school directors and 181 teachers in 17 schools. In fact, our survey targeted two sub-populations represented by a sample of school principals and a sample of teachers from these same institutions. Through this study, one took an analytical look that shed light on the importance of the human factor in the successful integration of ICT in education.

\section{Results}

To this end, it remains important to first situate the equipment in its context and see later how the skills and experiences of the faculty and the best mode of acquisition of computer skills in accordance with the use of ICT are structured. This part of the research will give way to the assessment of the situation by the directors of the institutions, with a view to proposing strategies to help teachers to use ICT. This evaluation, including, the judgment of the heads of institutions, will identify the main factors considered as obstacles to achieving the institution's ICT objectives.

\subsection{Equipment}

4.1.1 Number of students per computer

The results of the study reveal that majority of schools in our sample have not so far been equipped with computers that are used sustainably for teaching and / or made available to students. No significant difference can be observed between the three grades. One high school, among the 17 institutions, has a pupil / computer ratio of 21.5 and is the best ratio in the sample.

4.1.2 Number of computers available to teachers

More than three-fifths of the teachers surveyed said their schools did not provide computers. Only 62 teachers out of 181 surveyed said that computers are available to them in their institutions. However, one found a very low number per grade level, the highest number of fixed computers available to teachers is 8 , registered for primary schools, but they have no laptop computers. The number of computers available to teachers is lower in high schools. Indeed, concerning one's sample, the school that has the most computers, has 5 computers. The last staff, returns to the average level with only two computers.

4.1.3 Access to the computer and / or the Internet in the institution.

Indeed, with the exception of two schools, all computers in the schools surveyed are not connected to the Internet. Similarly, the number of computers connected to the Internet in these institutions is very small, at most, a computer connected for the middle and secondary levels. The results show that the proportion of teachers who have computers in their schools is very small. No real difference for the

internet in all institutions; it is almost non-existent. Regarding access to the computer, the highest share represents 57 teachers, who claimed the use of computers in computer rooms.

\subsection{Skills and Experiences of the Teaching Staff}

4.2.1 Private facilities

It is almost impossible to find among the respondents a teacher who has not already acquired a computer $(0.11 \%)$, just as $28.7 \%$ reported not having used a computer before. In fact, according to figure "1", $22,21 \%$ of teachers surveyed said that their most recent computers are less than three years old. More than half of the teachers personally own a fixed computer and less than a third own a laptop.

Figure 1. Possession of a computer

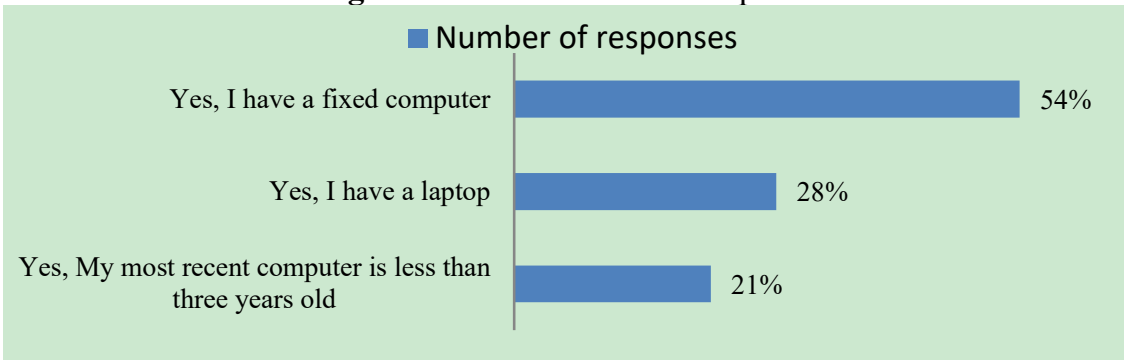

In addition, almost half of the teachers surveyed have no internet connection, less than a third has a slow connection. The lowest proportion $(23 \%)$ is for teachers who have a fast Internet connection.

4.2.2 Personal skills

On a scale of 1 (No knowledge) to 3 (very good knowledge), teachers estimated their own level of skills in different areas related to the use of ICT. The area where teachers feel most comfortable is: simple searches on the internet. 
In most other areas, teacher self-evaluation is fairly average.

4.2.3 The Best Way to Acquire Computer Skills

Teachers were asked to rank the six modes of acquisition of their computer skills in order of preference, which is illustrated in figure "3". In order of priority, the mode of acquisition of ICT skills with the help of family members or circle of friends ranked first. Second is the acquisition of ICT skills with "colleagues". The mode of acquisition of ICT skills in continuing education courses offered by private institutions ranked third.

Figure 2: The best way to acquire computer skills

With the help of my family member or circle of friends
With the help of colleagues
In continuing education courses offered by private..
During distance training scheduled for teachers
In-house continuing education course

\subsection{Use of ICT}

\subsubsection{Use of ICT for Education}

Nearly $11 \%$ of teachers use a computer or Internet less than once a month, for the purpose of teaching in the classroom where they teach. For the degree "never", it records the greatest frequency, almost (80\%) of the teachers consider never using the computer or internet for teaching and / or during their teaching. If one carries out the details of the activities involving the teacher directly, we find mostly no activity with a representative proportion. This mode of work is however not very marginally present in the respondents' responses.

4.4 Assessment of the Situation by Directors and Teachers

4.4.1 Teachers' Views on Computer Integration in Education

Teachers were also invited to give their opinion on the integration of ICT in education. Several statements about the relevance and expected impact of computer integration in education have been proposed in the questionnaire. The results showed that teachers agree on the positive impact that the integration of ICT can have in their teaching. The lowest proportion of the six proposals is estimated at $77 \%$ for "when I integrate a computer in my teaching, my preparation time is increased (okay)", the remaining proportions have exceeded $80 \%$ (okay).

4.4.2 Directors' views on the relevance and impact of ICT

Institutional leaders were invited to provide their views on the situation within their institution for various aspects of ICT: a series of aspects related to equipment. The assessment provided by the establishment managers is in all cases positive. Half of the principals are almost in agreement on: teachers are more likely to implement curriculum objectives through the use of ICT (53\%). Students are more attentive when using computers in the classroom and overall (47\%), ICT makes the curriculum more challenging and rewarding (59\%). The lowest rating is that students are not as productive when they use computers in the classroom. Indeed, the directors do not agree with (18\%) for the latter but they disagree with (59\%).

\subsubsection{Barriers to Achieving Institutional ICT Objectives}

The managers of the institutions surveyed were asked to comment on various points cited as obstacles to the achievement of the institution's ICT objectives. Figure « $9 »$ presents the different considerations of the directors. In fact, the lack of knowledge and know-how of the teaching staff concerning the use of computers for teaching purposes is identified in $71 \%$ of cases as an obstacle by school leaders, the same proportion is recorded for not enough training opportunities for teachers and lack of willingness and interest of teachers for knowledge in the field; and lack of maintenance and technical support. Then there is the insufficient number of computers for students $(65 \%)$ and the difficulty to set a schedule with enough time to computer learni for different classes $(65 \%)$. The other items bring together almost half of the school heads interviewed. 
Figure 3. Main Factors Considered as Obstacles to Achieving ICT Objectives by Facility Managers Interviewed

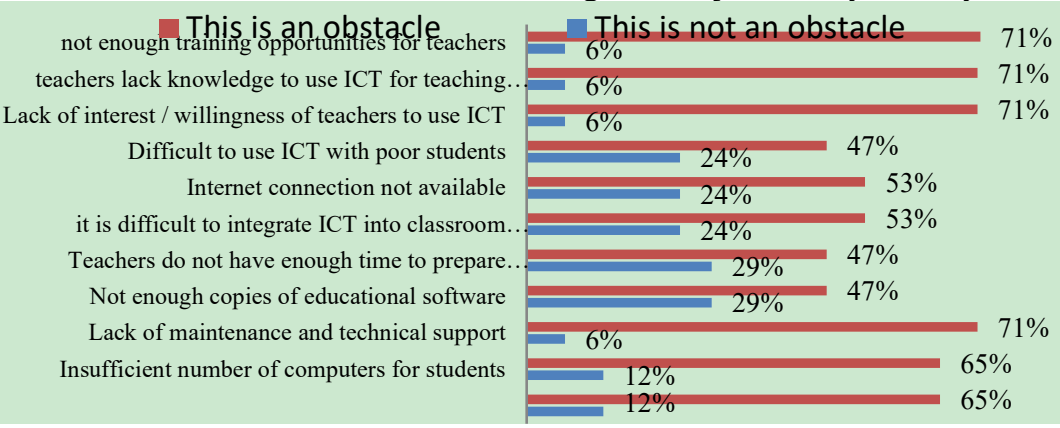

In fact, secondly, school head masters were asked to identify the three main obstacles presented in Figure "4". The following obstacles were mainly mentioned in order of ranking. Namely: 1- Lack of maintenance and technical support, 2- Lack of interest / willingness of teachers for the use of ICT and 3- Insufficient number of computers for students.

Figure 4 : The main obstacles

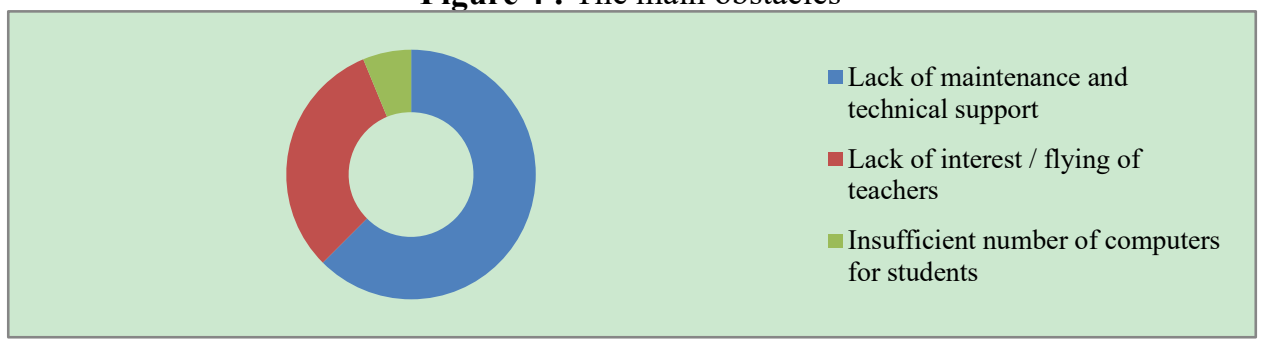

\section{Summary and Discussion of Results}

In Algeria, several operations to equip schools with the necessary material have been undertaken in recent years. To this end, one is interested in this research by the human factor substituted by the directors of institutions, teachers, and technical support staff. The latter is an essential component in the equation of ICT integration in education, even if a minimum of equipment is needed for the proper use of ICT in education. In addition, the most commonly used indicator for measuring students' ease of access to ICT in most surveys is the pupil-to-computer ratio. This indicator can help to estimate the minimum threshold, which is difficult for teachers to have a computer necessary for conducting activities involving the use of ICTs. It can also show how difficult it is for students to access a computer. As previously mentioned, the official statistics revealed in "2008" the following ratios: 1 PC for 36 high school students, for the secondary cycle, 1 PC for 118 middle school students, for the average cycle and $1 \mathrm{PC}$ for 5563 pupils, for the primary cycle (synthesis and -Algeria2013, 2008 1 ). By way of comparison, the magazine No. 2 of INRE ${ }^{2}$ published in the last quarter of 2011, declares the following ratios: 01 PC for 44 high school students and 01 PC for 120 middle school students. It is clear that from 2008 to 2011, the ratios decreased. Two explanations can be accepted in this case. If the number of pupils has increased in relation to the number of computers, the number of computers has decreased in relation to the number of pupils in the case of computer breakdowns.

Computer equipment has not kept pace with the growth in the number of students enrolled in recent years given the country's demographic development. This was made clear in the statements of the Minister of National Education of 21 September 2017; " the national education sector has more than 9 million students, nearly 27,000 schools in a territory of 2.5 million $\mathrm{km} 2$ and more than 700,000 civil servants. The overall student population has increased tenfold since independence, from just over 800,000 students in 1962 to more than 9 million students in 2017».

Compared to the results of our survey, we noted the lack of an average pupil / computer ratio. The data collected did not allow this ratio to be calculated for some schools, given the lack of computers in the latter. We had 500.5 students per computer at 21.5 students per computer. Moreover, it is the best ratio of the sample of 17 schools surveyed that remains very low. The question of the connection of computers to the Internet used by students, suffers from a low Internet speed and repeated cuts especially for wired networks. This situation means that the connection to the Internet is available in a limited number of computers or absent in the institution. However, the huge investments made in recent years have made it possible to connect some institutions to the Internet given the very large number of schools. In this sense, providing schools with computers and Internet connection is a priority in the education sector. According to the NWRI review, the generalization of the Internet

1 Online : http://www.algerianembassy.ru/pdf/e-algerie2013.pdf

2 INRE: Institut national de recherche en éducation National Institute for Educational Research 
to all institutions, once equipped with computer lab is the priority of the Ministry of Education. Indeed, the latter published in December 2011, a ministerial decree concerning the installation of a commission for monitoring and implementing the strategy «e-Education» (INRE, Op.cit).

Moreover, Algeria is making remarkable progress in terms of ICT development momentum, even though it has not yet occupy the best places for ICT development. The annual international ranking published in the 2017 report by the International Telecommunication Union $(\mathrm{ITU})^{1}$ ranks Algeria $102^{\text {nd }}$ in the world, with a $~\left\langle\mathrm{IDI}^{2} »\right.$ the ICT development index equal to 4.67, an increase of 4 places compared to 2016 when it ranked 106th. Likewise, the IDI increase of 0.34 has enabled it to occupy $22^{\text {nd }}$ place globally in IDI growth and the first at the Arab level. Therefore, this level is obtained after the satisfaction of certain criteria, such as, the connection to the Internet in the sense of allowing all citizens the use of ICT. Notably, the mobile Internet has progressed remarkably in recent years, recording a rate of change of $22 \%$ compared to the number of subscribers from 2016 to 2017, according to the report of the Regulatory Authority of the Post and Telecommunications (ARPT ${ }^{3}$ ). In the same report the number of subscribers accounted for $90,85 \%$ of a total of 3462551 mobile and fixed Internet subscribers. In this sense, teachers and school principals have the Internet, Smartphone and laptop in a private setting. Moreover, the results of one's survey, showed that it is almost impossible to find among teachers interviewed, a teacher, who has not already acquired a computer $(0.11 \%)$. In contrast, $28.7 \%$ reported not having used a computer before. This private equipment can help teachers research the Internet to expand and update their course. Similarly, several actions are undertaken by the Ministry of National Education to deal with this delay.

In this case, the platform of the CNIIPDTICE ${ }^{4}$ is in an advanced stage of its realization. The latter would guarantee educational institutions the best conditions for access to the Internet and provide assistance in the use of ICT. Likewise, it involves setting up a national training and certification program in accordance with the ICDL (International Computer Driving License) standard for education personnel. These types of training have already started since 2017, especially for online training for school heads and teachers. In addition, the tablet is already used in pilot schools, in classes called smart classes. Spreading its use in all schools is planned as the final result of this project. On the other hand, in one's survey the self-evaluation of teachers of their methodical and didactic skills of the integration of the computer in the teaching activities takes on a particular meaning. The area where teachers feel most comfortable is the simple search on the Internet. In most other areas, teacher self-evaluation is fairly average, with $70 \%$ of teachers reporting that they do not have knowledge of software installation. More surprisingly, teachers' self-assessment of their methodical and didactic skills of computer integration in teaching is only represented by $15 \%$ for very good knowledge. If we look at how these skills are acquired, we note that the acquisition of ICT skills is done mainly with the help of family members or circle of friends. At a much lower level, teachers state that they have acquired their skills in the distance learning course planned for teachers, during in-service training at the school and in courses organized by the Ministry of Education for teachers. On average, $5 \%$ of teachers took part in these courses. While one of the axes of the Ministry's strategy, in this case "eEducation", is the training of all the actors of the National Education (INR, Op.cit). One notes a huge deficit in teacher training. However, the Ministry is not the only responsible, we can say from the testimony of some teachers, that training sessions have been scheduled by the Ministry and teachers, who refused to attend. Some missed a lot of these sessions. Nevertheless, they admit to underestimating the importance of this training and say they are ready to catch up because they are now more than ever convinced that the future of education is with the use of ICT. Indeed, teachers use little ICT in their teaching. According to school principals, ICT is mainly used for modules in natural sciences and foreign languages. In the same perspective, if we indicate the details of the activities involving the teacher directly, we find mostly no activity with a representative proportion in the responses of the teachers surveyed. In addition, as part of this work, we asked principals to indicate the importance given by the school to different strategies to help teachers learn to use ICT. The training sessions (half-days or full days) are at the top of the list, in fact, this is the only strategy to have had positive responses from the directors. This proportion remains very low, they gave "little" importance to this strategy with $12 \%$. We were also amazed at how school principals perceive the effectiveness of the half-day or full-day ICT skills training strategy as "Not Effective". This result was verified by the chi-square test, which showed that this difference is more than $99 \%$ significant. Indeed, $40 \%$ of school principals consider the situation of ICTs in their school to be bad, and school principals feel that teachers' skills and the integration of ICT in education have changed little. These assessments are confirmed by the teachers. According to the heads of institutions, the biggest obstacle to the integration of ICT in the institutions to $71 \%$ is one of the three most important obstacles and it is that there is not enough staff to maintenance and technical support. Really, the maintenance of the ICT equipment of the establishment is essential

1 Online: https://www.itu.int/en/ITU-D/Statistics/Documents/publications/misr2017/MISR2017 ES F.pdf

2 IDI : Inclusive Development Index

3 ARPT : The Regulatory Authority of Post and Telecommunications was created in the context of the opening to competition of the post and telecommunications markets in Algeria, online : https://www.arpce.dz/fr/doc/pub/raa/raa_2017.pdf

4 CNIIPDTICE : National Center for the Integration of Educational Innovations and Development of Information and Communication Technologies in Education. 
to prolong the life of the equipment while keeping as long as possible the number of existing computers functional. However, the technical support is more essential because this position can be occupied by a computer technician mastering both the repair of small computer problems (installation, updated malicious software) and can solve the cuts of internet for internal reasons or to optimize the connection inside the establishment with good management of the internal network. The second obstacle considered by the directors on the three most important; is the lack of interest / willingness of teachers to use computers (70\%). Once again, the human factor embodied by teachers is a handicap to the realization of the use of the most coveted tool for the integration of ICT in education. In fact, if teachers are not motivated and decide to teach using computers by overcoming the difficulties of changing working methods, to convince them of the positive contributions of ICT for the teaching and learning of their pupils will not change the situation. The conditions for satisfactory ICT equipment cannot do anything on their own. Even if they are significant and non-negligible, in particular, ranked third in $(69 \%)$ by the establishment directors for the item; the insufficient number of computers. Although a snowmobile is required for snowmobiling, the pilot's skills, willingness and determination make it possible to slalom between trees and divert obstacles in order to reach their destination. However, these results demonstrate that the human factor is important for achieving ICT integration into education if teachers and principals do not have a good ICT level or a lower level than students. Thus, the delay in ICT equipment with schools that evolve and multiply from year to year without the development of ICT accompanies this growth, despite all the efforts made by the government in terms of access information and communication technologies. The human factor can reduce this delay by a strong will and dedication to successfully integrate ICT into education since most teachers and managers have equipment and a private internet connection that can be exploited inside or outside the school to integrate ICT into teaching and learning pending the finalization of the CNIIPDTICE platform. In addition, the Ministry should consider recruiting computer technicians into the institutions so that they can help teachers integrate the computer into their classes and use the technical problems that may arise. Indeed, if no one in the institution has the skills to solve the problems of computer, connection or maintenance of equipment the condition of satisfactory equipment will never be installed. Necessarily, these technicians can become a factor encouraging the integration of ICT in education. Finally, if there is cohesion among principals, teachers and staff for maintenance and technical support, this will be the most important asset for successful integration of ICT into education.

\section{Conclusion}

The topic of ICT integration is not only relevant, but it is a subject that is important to all education officials, researchers and specialists in the field because they are parents, and realizing the integration of ICTs into education can advance the level of the younger generation. As we have seen before, the authors attach great importance to this subject. They are investing in this cause and everyone is trying to find the solution. This is not a prodigious solution but a solution adapted to the needs and the situation encountered. Indeed, several ICT integration processes exist, and are applied all over the world. But those who gave more or less satisfaction are built on an approach surrounding the teacher because it is the actor most concerned. Integration is defined as the introduction of new elements to a system. It represents the creation of a form of unity or an identity bearing an image of renewal or repair. In education it takes the form of a human or material support. In addition, there are several models and experiences in several countries. However, their application requires a minimum of favorable conditions for the integration of ICTs at least, good equipment and initial and continuous training of teachers. However, experiences have shown that if the conditions for ICT integration are met, it does not necessarily mean that there will be ICT integration. The successful integration of ICT requires the involvement of all actors in education. The human being is the best asset to achieve the desired goals. The teacher is the actor and the most important factor in the integration of ICT in education, with its acceptance of change in its teaching practices. But also its investment in innovative methods, the integration of ICT in education will succeed better. Moreover, the human factor can reduce the delay in ICT equipment in Algeria with schools that evolve and multiply from year to year without the development of ICT accompanies following this growth, despite all efforts provided by the government in terms of access to information and communication technologies backed by a strong will and dedication to successfully integrate ICT into education. By using their private equipment as a complement to the establishment's ICT equipment until the CNIIPDTICE platform is finalized. In addition, the Ministry should consider recruiting computer technicians into the institutions so that they can help teachers integrate the computer into their classes and resort to technical problems that may arise. This will keep ICT equipment running for as long as possible and save teachers time for teaching. Inescapably, these technicians can become a factor encouraging the integration of ICT in education. Finally, if coordination will be established between principals, teachers and staff for maintenance and technical support, it will be the most important asset for any successful integration of ICT in education.

\section{References}

[1] Duarte-Cholat, "Tic et documentation : Etudes et reflexions sur des pratiques documentaires dans des CDI 
de collèges," Thèse de doctorat en Sciences de l'éducation -Université de paris V, 2000.

[2] Massou Luc et Morelli Pierre Kellner Catherine, "« (Re)penser le non-usage des tic », Questions de communication," Online http://tbi.crifpe.calfiles/Rapport.pdf: file:///C:/Users/amine/Downloads/questionsdecommunication-395.pdf, 2010.

[3] N., Coulombe, S., Giroux, P., Gauthier, D. et S. Gaudreault Cody, "Pratiques, objets et finalités de collaboration en lien avec l'intégration des tablettes numériques dans une école secondaire," Canadian Journal of Learning and Technologies, p. 42(3), 2016.

[4] Guihot Patrick, "Système Educatif et TIC, une difficile rencontrée," Texte adapté d'une communication au colloque d'Autrans «Ecole rurale, Communication et Technologies nouvelles, 1995.

[5] Karsenti Thierry \& Larouse François, "L'intégration pédagogique des TIC dans le travail enseignant," Recherches et pratiques presses de l'université du Québec, 2005.

[6] Thierry Karsenti, "Le tableau blanc interactif (TBI) : usages, avantages et défis?," Montréal : CRIFPE, Online http://tbi.crifpe.ca/files/Rapport.pdf, 2016.

[7] Stéphanie Boéchat-Heer, "Adaptation des enseignants aux usages des MITIC : sentiment d'auto-efficacité, formation et pratiques en classe," Haute école pédagogique, BEJUNE (Suisse), 2011.

[8] Lebrun, "La formation des enseignants aux TIC : allier pédagogie et innovation," online: http://www.ritpu.org/IMG/pdf/ritpu0101_lebrun.pdf, 2004.

[9] Isabelle Claire, Claire Lapointe, and Monique Chiasson, "Pour une intégration réussie des TIC à l'école : de la formation des directions à la formation des maîtres," Revue des sciences de l'éducation, pp. vol. $28, \mathrm{n}^{\circ} 2$, 2002.

[10] J Charlier, J Bonamy, and M Sauders, "Apprivoiser l'innovation. Dans B.Charlier et D. Perraya (dir.), Technologie et innovation en pédagogie. Dispositifs innovants de formation pour l'enseignement supérieur (p. 43-64). Bruxelles : De Boeck. ," 2003.

[11] Albert Strebelle Christian Depover, "Un modèle et une stratégie d'intervention en matière d'introduction des TIC dans le processus éducatif," Luc-Olivier Pochon, 2005.

[12] Akkari Abdeljalil Heer Stéphanie, "Intégration des TIC par les enseignants : premiers résultats d'une enquête suisse," Revue internationale des technologies en pédagogie universitaire, Online http://www.ritpu.org/IMG/pdf/akkarHeer.pdf., 2006.

[13] Schumacher Jérôme Coen Pierre-François, "Construction d'un outil pour évaluer le degré d'intégration des TIC dans l'enseignement," Revue internationale des technologies en pédagogie universitaire, online: www.profetic.org/revue, 2006.

[14] Larouse François Karsenti Thierry, "L'intégration pédagogique des TIC dans le travail enseignant: Recherches et pratiques presses de l'université du Québec.," 2005. 